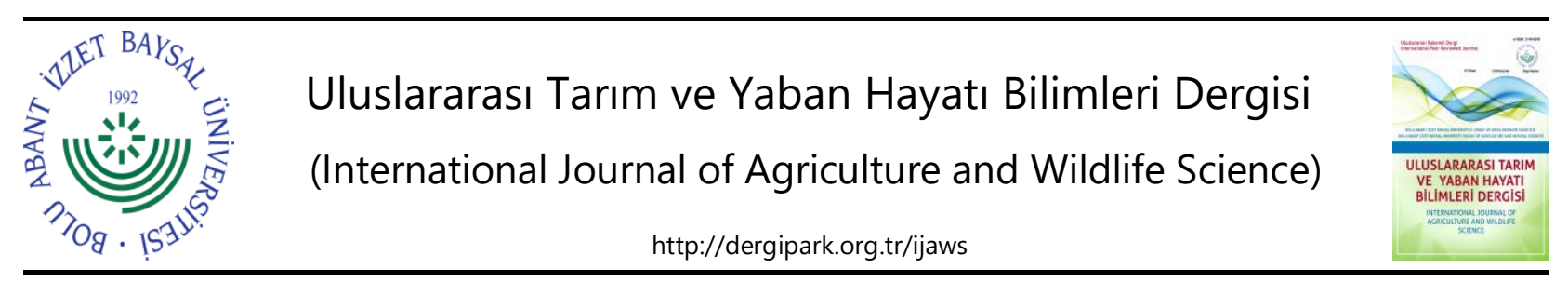

Araştırma Makalesi

\title{
Dut Türlerine Ait Meyvelerin Organik Asit ve C vitamini İçerikleri Üzerine Farklı Kurutma Tekniklerinin Etkisi ${ }^{* *}$
}

\author{
Müjde Kıralan ${ }^{1}$ (D)， Muttalip Gündoğdu ${ }^{2^{*}}$ \\ ${ }^{1}$ Bolu Abant İzzet Baysal Üniversitesi, Lisansüstü Eğitim Enstitüsü, Bolu \\ ${ }^{2}$ Bolu Abant İzzet Baysal Üniversitesi, Ziraat Fakültesi, Bahçe Bitkileri Bölümü, Bolu \\ Geliş tarihi (Received): 03.09.2021 Kabul tarihi (Accepted): 19.10.2021
}

\section{Anahtar kelimeler:}

Dut, organik asit, C vitamini,

kurutma yöntemleri

*Sorumlu yazar

gundogdumuttalip@gmail.com
Özet. Yapılan bu araştırmada, beyaz dut (M. alba) ve kara dut (M. nigra) meyveleri üç farklı şekilde kurutma işlemine tabi tutulmuştur. Bu yöntemler, güneşte kurutma, etüvde kurutma ( 70 , 90 ve $\left.110^{\circ} \mathrm{C}\right)$ ve mikrodalgada $(450,600$ ve $700 \mathrm{~W}$ ) kurutmadır. Kurutma işlemlerine bağlı olarak, meyve ağırlığı, nem oranı, C vitamini ve organik asit içeriklerindeki değişimler incelenmiştir. Güneşte kurutulan beyaz ve kara dut örneklerinde meyve ağırlığı sırası ile $1.07 \mathrm{~g}$ ve $1.59 \mathrm{~g}$ olarak bulunmuştur. Etüvde kurutmada meyve ağırlığı, beyaz dutlarda $0.57 \mathrm{~g}-0.88 \mathrm{~g}$, kara dutlarda 1.57 g-1.87 g aralığında, mikrodalgada kurutulan beyaz dutlarda $0.62 \mathrm{~g}-1.22 \mathrm{~g}$, kara dutlarda $0.76 \mathrm{~g}$ $1.41 \mathrm{~g}$ aralığında tespit edilmiştir. Kurutma yöntemlerine bağlı olarak organik asitlerin miktarlarında önemli değişimler görülmüştür. Beyaz dut meyvelerinde; en yüksek okzalik asit içeriği (2.88 $\left.\mathrm{g} 100 \mathrm{~g}^{-1}\right)$ güneşte kurutulan meyvelerde, en yüksek sitrik asit içeriği (14.15 g $100 \mathrm{~g}$ $\left.{ }^{1}\right)$ ve en yüksek malik asit içeriği $\left(17.67 \mathrm{~g} 100 \mathrm{~g}^{-1}\right)$ etüvde $\left(110{ }^{\circ} \mathrm{C}\right)$ kurutulan meyvelerde tespit edilmiştir. Kara dut meyvelerinin organik asit içerikleri incelendiğinde; en yüksek okzalik asit

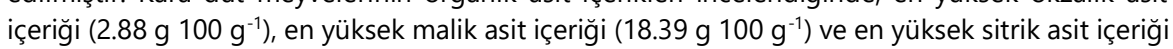
$\left(9.09 \mathrm{~g} 100 \mathrm{~g}^{-1}\right)$ güneşte kurutulan meyvelerde belirlenmiştir. En yüksek C vitamini içeriği (31.66 $\mathrm{mg} 100 \mathrm{~g}^{-1}$ ) yaş kara dut meyvelerinde tespit edilmiştir. Yapılan bu araştırmanın sonucunda, kurutma yöntemlerine bağlı olarak beyaz dut ve kara dut meyvelerinin biyokimyasal içeriklerinde önemli değişimlerin olduğu ve yaş meyvelerin kuru meyvelere göre $C$ vitamini içeriğinin daha yüksek olduğu belirlenmiştir.

\section{Effect of Different Drying Techniques on Organic Acid and Vitamin C Contents of Mulberry Species Fruits}

\section{Keywords:}

Mulberry, organic acid, vitamin

C, drying methods

\begin{abstract}
Black mulberry (M. nigra) and white mulberry (M. alba) fruits were dried in three different ways. These methods are drying in the sun, drying in the oven $\left(70,90\right.$ and $\left.110^{\circ} \mathrm{C}\right)$ and microwave (450, 600 and $700 \mathrm{~W}$ drying). Fruit weight, moisture content, vitamin $\mathrm{C}$ and organic acid contents changes depending on drying processes. Fruit weight is higher in microwave applications than other applications. In sun dried samples, white and black fruit weight were found as $1.07 \mathrm{~g}$ and $1.59 \mathrm{~g}$ respectively. In the dormitory drying, the fruit weight was $0.57 \mathrm{~g}-0.88$ $\mathrm{g}$ in the white mulberry, $1.57 \mathrm{~g}-1.87 \mathrm{~g}$ in the black mulberry, $0.62 \mathrm{~g}-1.22 \mathrm{~g}$ in the white mulberry in the microwave, and $0.76 \mathrm{~g}-1.41 \mathrm{~g}$ in the black mulberry. In the research, changes in the amount of organic acids were observed depended on drying methods. When looking the major organic

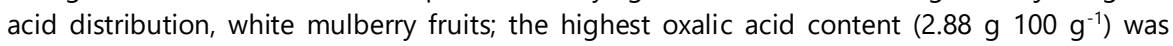
determined in sun dried fruits, the highest citric acid content $(14.15 \mathrm{~g} 100 \mathrm{~g}-1)$ and malic acid

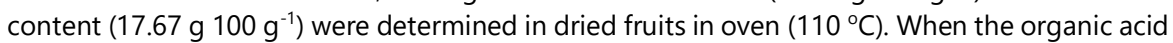

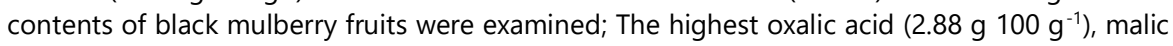

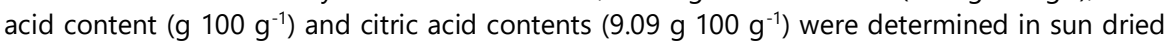

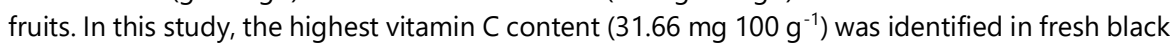
mulberry fruits. In this study, it was determined that there were significant changes in the biochemical contents of white mulberry and black mulberry fruits depending on the drying methods, and the vitamin $\mathrm{C}$ content of fresh fruits was higher than dried fruits.
\end{abstract}




\section{GíRiş}

Türkiye sahip olduğu coğrafik konumundan dolayı çok farklı iklim koşullarına sahiptir. Bu farklı ekolojik şartlar birçok meyvenin yetişmesini mümkün kılmaktadır. Özellikle üzümsü meyveler, Türkiye'de yetiştiriciliği yapılan meyveler arasında önemli bir yere sahiptir. (Ercişli, 2004). Urticales takımı, Moraceae familyası, Morus cinsi içerisinde yer alan dutun, dünya üzerinde birçok ülkede yetiştiriciliği yapılmaktadır. Dut bitkisinin 100'e yakın türü olduğu bildirilmektedir. Bu türlerden 10-12 tanesi ticari olarak yetişmektedir. Bunlardan 3 tanesi hem ticari açıdan hem de yayılım açısından önem arz etmektedir. Bunlar; Morus alba, Morus nigra ve Morus rubra'dır (Verheij ve Coronel, 1991, Koyuncu ve ark., 2004). Dut çeşitlerinin anavatanları da farklıık göstermektedir. M.alba L.'nın anavatanın Çin, M. nigra L.'nın İran ve Kafkaslar, M. rubra L.'nın ise Kuzey Amerika'dır (Erdoğan, 2003). Ülkemizde dört mevsimin yaşanması, meyve türlerinde zengin genetik kaynaklara ve biyolojik çeşitliliğe imkan sağladığı gibi dut türlerinin yetiştiriciliğinin de rahatıkla yapılabilmesine olanak sağlamaktadır. Kara dut (Morus nigra L.), kırmızı dut (Morus rubra L.) ve beyaz dut (Morus alba L.) ülkemizde yaygın olarak yetiştirilen dut türleridir. Dut popülasyonu açısından Anadolu önemli bir varyasyona sahiptir. Türkiye'de beyaz dutun diğer dut türlerine göre yetiştiriciliğinin daha yaygın olduğu görülmektedir (Ercişli, 2004). Dut; sanayide (pestil, pekmez, meyveli dondurma, reçel, ispirto, sirke, vb.) farmakolojide, kozmetikte, ve peyzajda (park ve bahçelerde) kullanılmaktadır. Beyaz dutun dağınık formlu ve manzara ağaçlar gurubunda yer aldığı belirtilirken peyzaj çalışmalarında kullanımı tercih edilen bir tür olduğu bildirilmiştir (Gündoğdu ve ark., 2011). İçerdiği yüksek antioksidan fitokimyasallar ve insan beslenmesine ve sağlığına katkılarından dolayı dut meyvelerinin popülaritesi gün geçtikçe artmaktadır (Ercişli ve Orhan, 2008; Koyuncu ve ark., 2014; Rop ve ark., 2014; Sanchez ve ark., 2014; Sanchez-Salcedo ve ark., 2015).

Gıda muhafaza yöntemleri arasında kurutma işlemi önemli bir yer tutmaktadır. Kurutma işlemi ile birlikte gıda ürünlerindeki serbest su uzaklaştırılarak mikroorganizma gelişimi, gıdalarda istenmeyen kimyasal reaksiyonlar durdurulmakta veya yavaşlatılmaktadır. Buna bağlı olarak kurutma işlemi gıda maddesinin dayanma süresini uzatmakta, ürün hacminin azalması ile depolama ve taşımada kolaylık sağlamaktadır (Evranuz, 1998). Kurutma yöntemlerine bakıldığında, mikrodalga uygulamasının geleneksel kurutma yöntemlerine göre ısıtma hızı yüksek ve işlem süresi oldukça kısadır. Mikrodalga uygulanan gıdalarda vitamin ve mineral kayıplarının daha az olduğu bildirilmiştir. Bunun yanında az yer kaplaması, kolay temizlenmesi ve enerji tasarrufu sağlanması da önemli avantajlarındandır (Oliveira ve ark., 2002).

Söz konusu bu araştırmada; Türkiye açısından önemli üzümsü meyvelerden olan kara dut ve beyaz dutun farklı kurutma teknikleri ile organik asitler ve C vitamini gibi meyvenin beslenme açısından önemli karakteristiklerindeki değişimler incelenmiştir. Kurutma teknikleri arasında güneşte kurutma, etüvde kurutma ve mikrodalgada kurutma yöntemleri uygulanmıştır. Yapılan bu araştırmada, kurutulmuş olarak piyasada yer alan dutların hangi kurutma tekniği kullanılarak en iyi beslenme değerine sahip olacağı belirlenmeye çalışılıışır.

\section{MATERYAL VE METOT}

Doğal kurutma işleminde meyveler gölgede serilerek belli nem oranına (\%16.94) kadar kurutulması sağlanmıştır. Etüvde ve mikrodalga kurutmada Juhaimi ve ark. (2017)'nin bildirdiği kurutma koşullarında çeşitli modifikasyonlar yapılarak uygulama yapılmıştır. Etüvde kurutma işleminde ise 70,90 ve $110{ }^{\circ} \mathrm{C}^{\prime}$ de üç farklı kurutma işlemi yapılmıştır. Mikrodalga kurutmada ise $450 \mathrm{~W}$ (4 dk), $600 \mathrm{~W}$ (3 dk) ve $700 \mathrm{~W}$ (3 dk) olmak üzere farklı uygulamalar yapılmıştır.

Kurutma işleminde meyvelerde nem tayini otomatik nem tayin cihazı ile yapılmıştır ve sonuçlar \% olarak sunulmuştur. Meyvelerin ağırlık kaybı ise $0.001 \mathrm{~g}$ 'a duyarlı hassas terazi ile ölçülmüştür. Yapılan araştırmada biyokimyasal analizlerde meyvelerin nem oranlarının farklı olmasından dolayı yöntemi optimize etmek için ağrılık nem oranına bağlı olarak her uygulamada alınan örnek miktarı standardize edilmiştir.

\section{Organik Asitlerin Analizi}

Yaş ve kurutulmuş örneklerde organik asitlerin ekstraksiyonu Bevilacqua ve Califano (1989)'nun bildirdiği yöntemin modifikasyonu ile yapılmıştır. $10 \mathrm{~g}$ örnek santrifüj tüplerine alınmış ve daha sonra $10 \mathrm{~mL} 0.009 \mathrm{~N} \mathrm{H}_{2} \mathrm{SO}_{4}$ örneklere ilave edilmiş ve homojenize edilmiştir. Örnekler 1 saat karıştııılmış ve 14.000 rpm'de 15 dakika santrifüjlenmiştir. Santrifüj tüpünün üst kısmında kalan sıv (süpernatant) filtre kâğıdından süzülmüş, akabinde 0.45 $\mu \mathrm{m}$ membran filtreden ve nihayetinde SEP-PAK C18 kartuşdan geçirilmiştir. HPLC (Agilent HPLC 1100 series $G$ 1322 A, Almanya) cihazına enjekte edilerek uygun kolonda (Aminex HPX - 87 H, 300 mm x 7.8 mm) ayrımları 
gerçekleştirilmiştir. Organik asitler 214 ve $280 \mathrm{~nm}$ dalga boylarında belirlenmiştir. Mobil faz olarak $0.009 \mathrm{~N} \mathrm{H}_{2} \mathrm{SO}_{4}$ çözeltisi kullanılmıştır.

\section{C vitamini Analizi}

Homojenizatörde parçalanan dut örneklerinin üzerine $5 \mathrm{~mL} \% 2.5 \mathrm{M}$-fosforik asit çözeltisi ilave edilmiştir. Elde edilen karışım $+4{ }^{\circ} \mathrm{C}^{\prime}$ de 6500 x g'de 10 dakika süre ile santrifüjlenmiştir. Santrifüj tüpündeki berrak kısımdan 0.5 $\mathrm{mL}$ alınarak ve \%2.5'lik M-fosforik asit çözeltisi ile $10 \mathrm{ml}$ 'ye tamamlanmıştır. Bu karışım $0.45 \mu \mathrm{m}^{\prime}$ lik teflon filtreden filtre edilerek HPLC cihazına enjekte edilmiştir. HPLC analizlerinde C vitamini C18 kolonda (Phenomenex Luna C18, $250 \times 4.60 \mathrm{~mm}, 5 \mu$ ) belirlenmiştir. Kolon fırını sıcaklığı $25^{\circ} \mathrm{C}$ olarak ayarlanmıştır. Sistemde mobil faz olarak $1 \mathrm{ml}$ dakika ${ }^{-1}$ akış hızında $\mathrm{pH}$ düzeyi $\mathrm{H}_{2} \mathrm{SO}_{4}$ ile $2.2^{\prime} \mathrm{e}$ ayarlanmış ultra saf su kullanılmıştır. Okumalar DAD dedektörde $254 \mathrm{~nm}$ dalga boyunda belirlenmiştir. C vitamini pikinin tanımlanması ve düzeyinin tespit edilmesinde farkı konsantrasyonlarda (50, 100, 500, 1000, 2000 ppm) hazırlanan L-askorbik asit (Sigma A5960) kullanılmıştır (Cemeroğlu, 2007).

\section{Istatistiksel Değerlendirme}

Kurutma işlemi sırasında değişimlerin incelenmesinde SPSS (23) paket programı kullanılmıştır. Kurutmaya bağlı olarak fenolik madde ve organik asitlerin değişiminin istatistiksel olarak değerlendirilmesinde Duncan çoklu karşılaştırma testi kullanılmış, gruplar arasındaki farklılıkların değerlendirilmesine ise tek yönlü varyans analizi (One-Way ANOVA) kullanılmıştır.

\section{BULGULAR VE TARTIŞMA}

\section{Nem ve Ağırlık}

Kurutma sırasında beyaz dut ve kara dut meyvelerine ait ağırlık ve nem verileri Çizelge 1 ve 2'de verilmiştir. Kara dut ve beyaz dutun yaş meyve ağırlıkları sırası ile 7.06 ve $2.67 \mathrm{~g}$ olarak belirlenmiştir. Güneşte kurutmada ağırlık beyaz dutta 1.07 g'a kara dutta ise 1.59 g'a kadar düşüş göstermiştir. Beyaz dutta etüvde kurutma yönteminde $110{ }^{\circ} \mathrm{C}^{\prime}$ da ağırlıkta en fazla kayıp gerçekleşmiş olup, $0.57 \mathrm{~g}$ olarak tespit edilmiştir. 70 ve $90{ }^{\circ} \mathrm{C}$ sıcaklıklardaki uygulamalarda sırası ile meyve ağırlıkları $0.88 \mathrm{~g}$ ve $0.58 \mathrm{~g}$ olarak belirlenmiştir. Mikrodalga kurutmada beyaz dutta en fazla ağırlık kaybı $450 \mathrm{~W}$ güçte 4 dakika uygulamada tespit edilmiştir $(0.62 \mathrm{~g})$. Beyaz dutta $600 \mathrm{~W}$ güçte 3 dakika uygulamada ağırlık 0.89 g'a $700 \mathrm{~W}$ güçte 3 dakika uygulamada ise 1.22 g'a kadar düşüş sağlanmıştır. Kara dutta etüvde kurutma yönteminde en fazla ağılık kaybı $70^{\circ} \mathrm{C}$ 'da gerçekleşmiş ve ağılık $1.57 \mathrm{~g}$ olarak belirlenmiştir. 70 ve $90^{\circ} \mathrm{C}$ sıcaklıklardaki uygulamalarda ise kara dut ağırlıkları sırası ile $1.87 \mathrm{~g}$ ve 1.80 g olarak belirlenmiştir. Kara dutların mikrodalga ile kurutulmasında en fazla meyve ağırlığı $1.41 \mathrm{~g}$ ile $700 \mathrm{~W} 4.5$ dakika uygulamada, en az meyve ağırlığı ise $0.76 \mathrm{~g}$ ile $450 \mathrm{~W}$ güçte 7 dakika uygulamada tespit edilmiştir. Güneş ve Çekiç (2004), 5 farklı kara dut genotipinde meyve ağırlığının 3.02 g- 5.72 g aralı̆ı̆ıda, 23 farklı beyaz genotipte ise $3.15 \mathrm{~g}-6.88 \mathrm{~g}$ aralığında değişim gösterdiğini bildirmişlerdir. Ercişli ve Orhan (2007) yaptıkları çalışmada Erzurum'da yetişen M. alba ve M. nigra dut çeşitlerinde yaş meyve ağırlıklarını sırası ile $3.49 \mathrm{~g}$ ve $4.37 \mathrm{~g}$ olarak belirlemişlerdir. Iğdır, Tuzluca ve Kağızman ekolojik koşullarında yetişen kara dut meyvelerinde meyve ağırlığı 2.19 g-3.58 g arasında belirlenmiştir (Pehluvan ve ark., 2012). Uşak ili Ulubey ilçesinde yapılan çalışmada 15 adet kara dut genotipinde yaş meyve ağırlıkları $2.87 \mathrm{~g}-4.30 \mathrm{~g}$ arasında tespit edilmiştir (Erkaleli ve Dalkılıç, 2016). Kara dut meyvesi için çalışmalarda tespit edilen meyve ağırlıkları, Güneş ve Çekiç (2004), Ercişli ve Orhan (2007), Pehluvan ve ark. (2012), Erkaleli ve Dalkılıç (2016)'ın bildirdiği ağırlıkların üzerinde belirlenmiştir. Bu farklılığın özellikle meyvelerin toplandığı lokasyon ve ekolojik koşullardan kaynaklandığı düşünülmektedir. Çalışmada yaş beyaz dut meyve ağırlıkları, Güneş ve Çekiç (2004), Ercişli ve Orhan (2007)'ın bildirdiği verilerin altındadır. Yine bu farklıı̆ın kara dutta olduğu gibi lokasyon ve ekolojik şartlardan kaynaklı olduğu düşünülmektedir. Beyaz dut ve kara dutun yaş meyvede nem oranları sırası ile \%83.63 ve \% 91.97 olarak belirlenmiştir. Güneşte kurutma ile nem oranları beyaz dutta \%17.87'ye kara dutta ise \% 16.94'e kadar düşmüştür. Beyaz dutun etüvde kurutulmasında en düşük nem oranı $\% 13.73$ ile $110{ }^{\circ} \mathrm{C}$ 'de gerçekleşirken en fazla nem oranı ise \% 29.51 ile $70{ }^{\circ} \mathrm{C}$ 'deki uygulamada tespit edilmiştir. Mikrodalga uygulamada ise beyaz dutlarda en fazla nem kaybı \%55.76 ile $450 \mathrm{~W}$ gücün 4 dakika uygulandığı örnekte belirlenmiştir. Bu yöntem ile kurutmada en fazla nem oranı \%67.21 ile $700 \mathrm{~W}$ gücün 3 dakika uygulandığı örnekte tespit edilmiştir. Kara dutta etüvde kurutma yönteminde en yüksek nem oranı \%44.92 ile 90 ${ }^{\circ} \mathrm{C}^{\prime} \mathrm{da}$, en düşük nem oranı ise $\% 25.70$ ile $70{ }^{\circ} \mathrm{C}$ 'da uygulamada belirlenmiştir. Kara dutun mikrodalga ile kurutulduğu yöntemde ise en düşük nem oranı (\% 44.00) ile $450 \mathrm{~W}$ güçte 7 dakika uygulamada, en yüksek nem oranı ise \%64.05 ile $700 \mathrm{~W}$ güçte 4.5 dakika uygulamada tespit edilmiştir. Ercişli ve Orhan (2007) yaptıkları çalışmada Erzurumda yetişen M. alba ve M. nigra dut türlerinde nem oranları sırası ile \%71.5 ve \% 72.6 olarak 
belirlenmiştir. Çoruh Vadisi'nde M. alba genotiplerinde yapılan çalışmada meyvelerde nem oranının \%72.85-79.75 aralığında değişim gösterdiği belirlenmiştir (Güngör ve Sengul, 2008). Pakistan'da yapılan çalışmada M. alba ve M. nigra genotiplerinin meyvelerinde nem oranı sırasıyla \%81.72 ve \% 82.40 olarak tespit edilmiştir (Imran ve ark., 2010). Türkiye'nin Isparta ili Mahmutlar lokasyonunda 8 kara dut genotipinde yapılan çalışmada nem oranı \%77.30 ile \% 84.27 arasında belirlenmiştir (Koyuncu ve ark., 2014). Uşak ili Ulubey ilçesinde yapılan çalışmada 15 adet kara dut genotipinde nem oranı \%69.3-78.4 olarak belirlenmiştir (Erkaleli ve Dalkılıç, 2016). Çalışmada beyaz dut meyvesinde belirlenen nem oranı (\%83.63), Ercişli ve Orhan (2007), Güngör ve Sengul (2008), Imran ve ark. (2010)'nın çalışmalarında bildirmiş olduğu değerlerden daha yüksek bulunmuştur. Kara dut için çalışmada bildirilen nem oranı (\%91.97), Ercişli ve Orhan (2007), Imran ve ark. (2010), Koyuncu ve ark. (2014), Erkaleli ve Dalkılıç (2016)'ın bildirdiği değerlerden yüksek bulunmuştur. Çalışma sonuçları ile literatür arasındaki farklılığın lokasyondan, uygulama farklılıklarından, ekolojik koşullardan ve genotip farklılığından kaynaklı olabileceği düşünülmektedir. Mikrodalga uygulamalarında nem oranı diğer klasik uygulamalara kıyasla daha yüksek bulunmuştur. Bu durum mikrodalga uygulama ile meyvenin dış yüzeyinde ani bir kuruma gerçekleşmesi ve dolayısı ile nemi dışarıya verememesinden kaynaklandığı düşünülmektedir. Juhaimi ve ark. (2017) çalışmalarında hurma meyvesini, güneşte, etüvde ve mikrodalga ile kurutmuşlardır. Güneşte kurutma ile birlikte nem kaybının çok fazla olduğu tespit edilmiştir. Mikrodalga kurutmada ise nem kaybı daha az olmakta, etüvde kurutmada ise nem kaybı mikrodalgaya nazaran daha fazla, güneşte kurutmaya göre ise daha az bulunmuştur. Meyvelerin gerek fizyolojik yapıları gerekse de nem oranları farkı olmasından dolayı doğrudan bir kıyaslama yapılamasa da sonuçların çalışmamıza benzer olduğu görülmektedir.

Çizelge 1. Kara dut (Morus nigra L.) meyvelerinin ağırlık ve nem oranları.

Table 1. Weight and moisture ratios of black mulberry (Morus nigra L.) fruits.

\begin{tabular}{|c|c|c|c|}
\hline Uygulamalar & & Ağırlık (g) & Nem (\%) \\
\hline \multirow{3}{*}{ Mikrodalga kurutma } & 450 W 4 dakika & $0.76 \pm 0.11 d^{*}$ & $44.00 \pm 2.05 c$ \\
\hline & 600 W 3 dakika & $1.30 \pm 0.16 c$ & $63.53 \pm 1.15 b$ \\
\hline & 700 W 3 dakika & $1.41 \pm 0.28 c$ & $64.05 \pm 1.02 b$ \\
\hline \multirow{3}{*}{ Etüvde kurutma } & $70^{\circ} \mathrm{C}$ & $1.57 \pm 0.25 b c$ & $25.70 \pm 4.05 \mathrm{~d}$ \\
\hline & $90^{\circ} \mathrm{C}$ & $1.87 \pm 0.33 b$ & $44.92 \pm 3.59 c$ \\
\hline & $110^{\circ} \mathrm{C}$ & $1.80 \pm 0.27 b$ & $31.16 \pm 5.29 d$ \\
\hline \multicolumn{2}{|l|}{ Güneşte kurutma } & $1.59 \pm 0.21 b c$ & $16.94 \pm 4.15 \mathrm{e}$ \\
\hline \multicolumn{2}{|l|}{ Yaş } & $7.06 \pm 0.44 \mathrm{a}$ & $91.97 \pm 4.43 \mathrm{a}$ \\
\hline
\end{tabular}

${ }^{*}$ Aynı sütunda, farklı harfle gösterilen ortalamalar arasındaki fark $\mathrm{P} \leq 0.05$ seviyesinde önemlidir.

Çizelge 2. Beyaz dut (Morus alba L.) meyvelerinin ağırlık ve nem oranları.

Table 1. Weight and moisture ratios of white mulberry (Morus alba L.) fruits.

\begin{tabular}{|c|c|c|c|}
\hline Uygulamalar & & Ağırlık (g) & Nem (\%) \\
\hline Mikrodalga kurutma & $\begin{array}{l}450 \text { W } 4 \text { dakika } \\
600 \text { W } 3 \text { dakika } \\
700 \text { W } 3 \text { dakika }\end{array}$ & $\begin{array}{c}0.62 \pm 0.09 d^{*} \\
0.89 \pm 0.11 c \\
1.22 \pm 0.14 b\end{array}$ & $\begin{array}{l}55.76 \pm 3.18 d \\
63.53 \pm 4.77 c \\
67.21 \pm 4.63 b\end{array}$ \\
\hline Etüvde kurutma & $\begin{array}{l}70^{\circ} \mathrm{C} \\
90^{\circ} \mathrm{C} \\
110^{\circ} \mathrm{C}\end{array}$ & $\begin{array}{l}0.88 \pm 0.07 c \\
0.58 \pm 0.13 d \\
0.57 \pm 0.17 d\end{array}$ & $\begin{array}{l}29.51 \pm 1.37 \mathrm{e} \\
15.49 \pm 1.11 \mathrm{fg} \\
13.73 \pm 1.01 \mathrm{~g}\end{array}$ \\
\hline \multicolumn{2}{|l|}{ Güneşte kurutma } & $1.07 \pm 0.13 b c$ & $17.87 \pm 2.12 f$ \\
\hline Yaş & & $2.67 \pm 0.38 a$ & $83.63 \pm 4.55 a$ \\
\hline
\end{tabular}

*Aynı sütunda, farkı harfle gösterilen ortalamalar arasındaki fark $\mathrm{P} \leq 0.05$ seviyesinde önemlidir.

\section{Organik Asitler ve C Vitamini}

Örneklerde altı farklı organik asit ve $\mathrm{C}$ vitamini (askorbik asit) belirlenmiştir. Belirlenen organik asitler; okzalik asit, sitrik asit, tartarik asit, malik asit, süksinik asit ve fumarik asittir. Kurutma yöntemlerine bağlı olarak organik asitlerin bileşimlerinde değişiklikler tespit edilmiş ve istatistiki olarak önemli farklılıklar bulunmuştur $(\mathrm{P}<0.05)$. Yaş

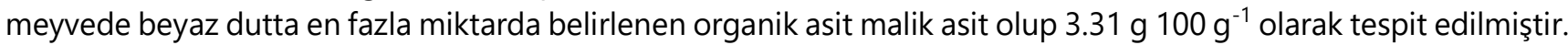

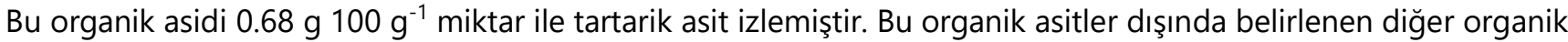

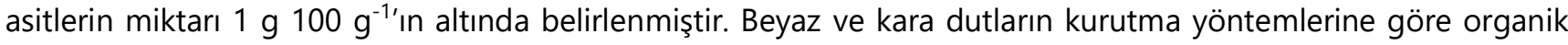
asit bileşimindeki değişim Çizelge 3,4,5 ve 6'da gösterilmiştir. Yaş meyvede en fazla miktarda belirlenen organik asit malik asit olup kurutma ile birlikte artış göstermiştir. Kurutma işlemleri kıyaslandığında en fazla artış etüvde

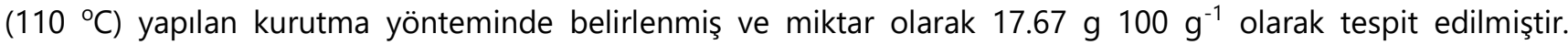


Mikrodalga ile kurutulmuş beyaz dutların malik asit içeriği güneşte kurutulan meyvelere göre daha fazla bulunmuştur. Mikrodalga ile kurutulan beyaz dut meyvelerinde en fazla malik asit artışı $600 \mathrm{~W}$ uygulamasında (16.30 g $100 \mathrm{~g}^{-1}$ ) belirlenirken en az artış ise $450 \mathrm{~W}$ uygulamasında (12.68 g $100 \mathrm{~g}^{-1}$ ) görülmüştür (Çizelge 5). Okzalik asit miktarı kurutma ile birlikte bir miktar artış göstermiştir. En fazla artış güneşte kurutma yönteminde

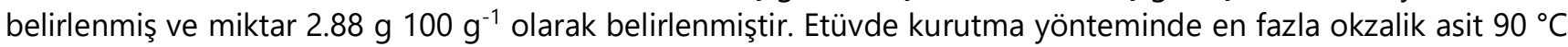

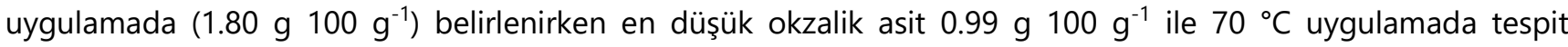
edilmiştir.

Çizelge 3. Kara dut (Morus nigra L.) meyvelerinin okzalik, sitrik, tartarik ve malik asit içerikleri.

Table 3. Oxalic, citric, tartaric and malic acid contents of black mulberry (Morus nigra L.) fruits.

\begin{tabular}{|c|c|c|c|c|c|}
\hline Uygulamalar & & $\begin{array}{c}\text { Okzalik } \\
\left(\mathrm{g} 100 \mathrm{~g}^{-1}\right)\end{array}$ & $\begin{array}{c}\text { Sitrik } \\
\left(\mathrm{g} 100 \mathrm{~g}^{-1}\right) \\
\end{array}$ & $\begin{array}{c}\text { Tartarik } \\
\left(\mathrm{g} 100 \mathrm{~g}^{-1}\right) \\
\end{array}$ & $\begin{array}{c}\text { Malik } \\
\left(\mathrm{g} 100 \mathrm{~g}^{-1}\right)\end{array}$ \\
\hline \multirow{3}{*}{ Mikrodalga kurutma } & 450 W 4 dakika & $1.90 \pm 0.05 b^{*}$ & $8.80 \pm 0.15 a$ & $0.48 \pm 0.07 a b$ & $15.37 \pm 0.17 c$ \\
\hline & 600 W 3 dakika & $0.45 \pm 0.02 \mathrm{fg}$ & $7.60 \pm 0.26 c$ & $0.48 \pm 0.03 a b$ & $12.55 \pm 0.15 \mathrm{e}$ \\
\hline & 700 W 3 dakika & $0.51 \pm 0.02 f$ & $5.82 \pm 0.07 \mathrm{e}$ & $0.50 \pm 0.04 a$ & $10.09 \pm 0.09 f$ \\
\hline \multirow{3}{*}{ Etüvde kurutma } & $70^{\circ} \mathrm{C}$ & $1.49 \pm 0.12 c$ & $8.28 \pm 0.10 b$ & $0.46 \pm 0.08 a b$ & $17.27 \pm 0.11 b$ \\
\hline & $90^{\circ} \mathrm{C}$ & $0.88 \pm 0.02 d$ & $5.34 \pm 0.14 \mathrm{f}$ & $0.37 \pm 0.03 c$ & $13.28 \pm 0.09 d$ \\
\hline & $110^{\circ} \mathrm{C}$ & $0.74 \pm 0.03 \mathrm{e}$ & $6.41 \pm 0.12 d$ & $0.47 \pm 0.01 \mathrm{ab}$ & $9.29 \pm 0.09 \mathrm{~g}$ \\
\hline \multicolumn{2}{|l|}{ Güneşte kurutma } & $2.88 \pm 0.09 a$ & $9.09 \pm 0.14 a$ & $0.43 \pm 0.02 b c$ & $18.39 \pm 0.11 a$ \\
\hline \multicolumn{2}{|l|}{ Yaş } & $0.36 \pm 0.03 \mathrm{~g}$ & $2.47 \pm 0.05 \mathrm{~g}$ & $0.28 \pm 0.00 \mathrm{~d}$ & $5.87 \pm 0.08 \mathrm{~h}$ \\
\hline
\end{tabular}

*Aynı sütunda, farkı harfle gösterilen ortalamalar arasındaki fark $\mathrm{P} \leq 0.05$ seviyesinde önemlidir.

Çizelge 4. Kara dut (Morus nigra L.) meyvelerinin süksinik asit, fumarik asit ve $C$ vitamini içerikleri. Table 4. Succinic acid, fumaric acid and vitamin C contents of black mulberry (Morus nigra L.) fruits.

\begin{tabular}{|c|c|c|c|c|}
\hline Uygulamalar & & Süksinik (g $100 \mathrm{~g}^{-1}$ ) & Fumarik (g $100 \mathrm{~g}^{-1}$ ) & Vitamin $C\left(m g 100 \mathrm{~g}^{-1}\right)$ \\
\hline \multirow{3}{*}{ Mikrodalga kurutma } & 450 W 4 dakika & $0.87 \pm 0.02 a^{*}$ & $0.55 \pm 0.02 c$ & $25.96 \pm 0.23 b$ \\
\hline & 600 W 3 dakika & $0.65 \pm 0.04 \mathrm{de}$ & $0.47 \pm 0.05 \mathrm{~cd}$ & $17.55 \pm 0.18 c$ \\
\hline & 700 W 3 dakika & $0.71 \pm 0.06 \mathrm{~cd}$ & $0.45 \pm 0.03 d$ & $15.28 \pm 0.24 d$ \\
\hline \multirow{3}{*}{ Etüvde kurutma } & $70^{\circ} \mathrm{C}$ & $0.93 \pm 0.08 a$ & $0.78 \pm 0.07 a$ & $15.37 \pm 0.20 d$ \\
\hline & $90^{\circ} \mathrm{C}$ & $0.74 \pm 0.03 c$ & $0.23 \pm 0.04 \mathrm{e}$ & $13.58 \pm 0.09 \mathrm{e}$ \\
\hline & $110^{\circ} \mathrm{C}$ & $0.63 \pm 0.04 \mathrm{e}$ & $0.27 \pm 0.03 \mathrm{e}$ & $12.19 \pm 0.07 f$ \\
\hline \multicolumn{2}{|l|}{ Güneşte kurutma } & $0.85 \pm 0.09 b$ & $0.65 \pm 0.04 b$ & $15.73 \pm 0.11 d$ \\
\hline \multicolumn{2}{|l|}{ Yaş } & $0.48 \pm 0.07 f$ & $0.11 \pm 0.00 \mathrm{f}$ & $31.66 \pm 0.29 a$ \\
\hline
\end{tabular}

*Aynı sütunda, farkıı harfle gösterilen ortalamalar arasındaki fark $\mathrm{P} \leq 0.05$ seviyesinde önemlidir.

Okzalik asitteki en az artış mikrodalga uygulamalarında görülmüştür. İstatistiki olarak tüm uygulamalar aynı grup içerisinde yer almış ve 0.97-1.16 g $100 \mathrm{~g}^{-1}$ aralığında tespit edilmiştir. Sitrik asit miktarı kurutma işlemine

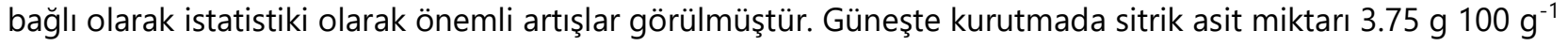
olarak tespit edilmiştir. 
Çizelge 5. Beyaz dut (Morus alba L.) meyvelerinin okzalik, sitrik, tartarik ve malik asit içerikleri. Table 5. Oxalic, citric, tartaric and malic acid contents of white mulberry (Morus alba L.) fruits.

\begin{tabular}{|c|c|c|c|c|c|}
\hline \multicolumn{2}{|l|}{ Uygulamalar } & $\begin{array}{l}\text { Okzalik } \\
\left(\mathrm{g} 100 \mathrm{~g}^{-1}\right)\end{array}$ & $\begin{array}{c}\text { Sitrik } \\
\left(\mathrm{g} 100 \mathrm{~g}^{-1}\right)\end{array}$ & 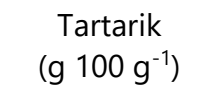 & 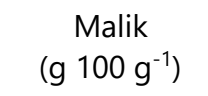 \\
\hline \multirow{3}{*}{ Mikrodalga kurutma } & 450 W 4 dakika & $0.97 \pm 0.1 d^{*}$ & $3.42 \pm 0.11 \mathrm{e}$ & $0.84 \pm 0.06 b c$ & $12.68 \pm 0.21 d$ \\
\hline & 600 W 3 dakika & $1.16 \pm 0.05 \mathrm{~d}$ & $5.52 \pm 0.18 d$ & $0.88 \pm 0.07 b$ & $16.30 \pm 0.31 b$ \\
\hline & 700 W 3 dakika & $1.00 \pm 0.02 \mathrm{~d}$ & $6.03 \pm 0.14 c$ & $0.83 \pm 0.05 b c$ & $15.45 \pm 0.16 c$ \\
\hline \multirow{3}{*}{ Etüvde kurutma } & $70^{\circ} \mathrm{C}$ & $0.99 \pm 0.06 \mathrm{~d}$ & $3.88 \pm 0.19 \mathrm{e}$ & $0.87 \pm 0.07 b$ & $10.95 \pm 0.19 \mathrm{e}$ \\
\hline & $90^{\circ} \mathrm{C}$ & $1.80 \pm 0.11 b$ & $10.32 \pm 0.25 b$ & $0.75 \pm 0.02 c$ & $16.84 \pm 0.24 b$ \\
\hline & $110^{\circ} \mathrm{C}$ & $1.45 \pm 0.04 c$ & $14.15 \pm 0.21 a$ & $0.71 \pm 0.03 c$ & $17.67 \pm 0.11 \mathrm{a}$ \\
\hline \multicolumn{2}{|l|}{ Güneşte kurutma } & $2.88 \pm 0.18 a$ & $3.75 \pm 0.15 \mathrm{e}$ & $3.60 \pm 0.15 a$ & $4.66 \pm 0.16 f$ \\
\hline \multicolumn{2}{|l|}{ Yaş } & $0.36 \pm 0.07 \mathrm{e}$ & $0.65 \pm 010 f$ & $0.68 \pm 0.10 d$ & $3.31 \pm 0.14 \mathrm{~g}$ \\
\hline
\end{tabular}

*Aynı sütunda, farklı harfle gösterilen ortalamalar arasındaki fark $\mathrm{P} \leq 0.05$ seviyesinde önemlidir.

Çizelge 6. Beyaz dut (Morus alba L.) meyvelerinin süksinik asit, fumarik asit ve $C$ vitamini içerikleri. Table 6. Succinic acid, fumaric acid and vitamin C contents of white mulberry (Morus alba L.) fruits.

\begin{tabular}{|c|c|c|c|c|}
\hline Uygulamalar & & $\begin{array}{l}\text { Süksinik } \\
\left(\mathrm{g} 100 \mathrm{~g}^{-1}\right)\end{array}$ & $\begin{array}{c}\text { Vitamin C } \\
\left(\mathrm{mg} 100 \mathrm{~g}^{-1}\right)\end{array}$ & $\begin{array}{l}\text { Fumarik } \\
\left(\mathrm{g} 100 \mathrm{~g}^{-1}\right)\end{array}$ \\
\hline \multirow{3}{*}{ Mikrodalga kurutma } & 450 W 4 dakika & $0.99 \pm 0.07 e^{*}$ & $17.48 \pm 0.41 \mathrm{~b}$ & $0.08 \pm 0.00 f$ \\
\hline & 600 W 3 dakika & $1.76 \pm 0.15 c$ & $16.51 \pm 0.24 c$ & $0.14 \pm 0.01 c$ \\
\hline & 700 W 3 dakika & $0.79 \pm 0.05 \mathrm{e}$ & $16.40 \pm 0.11 c$ & $0.10 \pm 0.00 \mathrm{e}$ \\
\hline \multirow{3}{*}{ Etüvde kurutma } & $70^{\circ} \mathrm{C}$ & $1.87 \pm 0.16 c$ & $18.26 \pm 0.17 b$ & $0.20 \pm 0.01 b$ \\
\hline & $90^{\circ} \mathrm{C}$ & $2.69 \pm 0.21 b$ & $14.37 \pm 0.09 d$ & $0.13 \pm 0.00 \mathrm{~d}$ \\
\hline & $110^{\circ} \mathrm{C}$ & $1.35 \pm 0.18 d$ & $11.34 \pm 0.16 f$ & $0.10 \pm 0.00 \mathrm{e}$ \\
\hline \multicolumn{2}{|l|}{ Güneşte kurutma } & $3.24 \pm 0.13 a$ & $13.40 \pm 0.16 \mathrm{e}$ & $1.31 \pm 0.13 a$ \\
\hline \multicolumn{2}{|l|}{ Yaş } & $0.60 \pm 0.04 \mathrm{f}$ & $26.30 \pm 0.14 a$ & $0.07 \pm 0.04 f$ \\
\hline
\end{tabular}

*Aynı sütunda, farklı harfle gösterilen ortalamalar arasındaki fark $\mathrm{P} \leq 0.05$ seviyesinde önemlidir.

Etüvde kurutma yöntemlerinde sıcaklık arttıkça sitrik asit miktarında artış olmuştur. En yüksek sitrik asit miktarı $14.15 \mathrm{~g} 100 \mathrm{~g}^{-1}$ ile $110{ }^{\circ} \mathrm{C}^{\prime} \mathrm{da}$ yapılan uygulamada, en düşük sitrik asit miktarı ise $3.88 \mathrm{~g} 100 \mathrm{~g}^{-1}$ ile $70{ }^{\circ} \mathrm{C}^{\prime} \mathrm{da}$ yapılan uygulamada tespit edilmiştir. Mikrodalga ile yapılan uygulamalarda sitrik asit miktarı etüvde kurutma yöntemine nazaran daha düşük bulunmuştur. Güç uygulamasına paralel olarak sitrik asit miktarında artış tespit edilmiştir. En

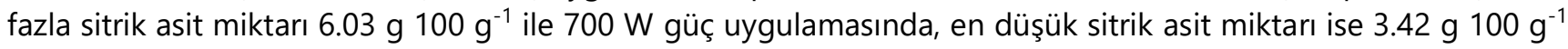
ile $450 \mathrm{~W}$ güç uygulamasında belirlenmiştir. Tartarik asit miktarı kurutma yöntemlerine göre artma eğilimi göstermiştir. Güneşte kurutma yönteminde tartarik asit miktarı $3.60 \mathrm{~g} 100 \mathrm{~g}^{-1}$ tespit edilmiştir. Etüvde kurutma

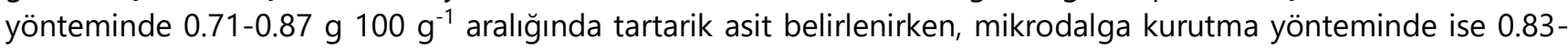

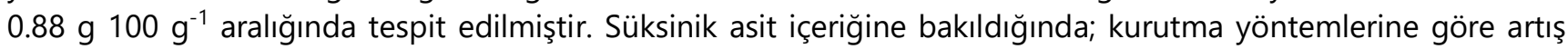

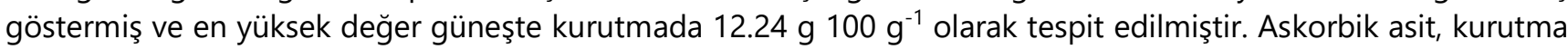
ile birlikte azalış gözlemlenen organik asitlerdendir. Askorbik asit miktarı güneşte kurutmada $13.40 \mathrm{mg}^{100 \mathrm{~g}^{-1}}$ olarak tespit edilmiştir. Askorbik asit miktarı, etüvde kurutma yönteminde, sıcaklık uygulaması artışına bağlı olarak

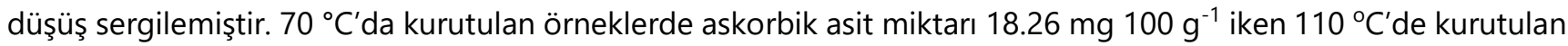
örneklerde ise $11.34 \mathrm{mg} 100 \mathrm{~g}^{-1}$ olarak belirlenmiştir. Mikrodalga kurutmada kurutma gücüne bağlı olarak askorbik asit az da olsa düşüş sergilemiştir. Mikrodalga kurutmada askorbik asit miktarı 16.40-17.48 mg $100 \mathrm{~g}^{-1}$ aralığında değişim göstermiştir. Beyaz dutların kurutulmasında fumarik asit de tartarik asidin gösterdiği eğilimi sergilemiştir. Güneşte kurutmada, fumarik asit miktarı $\left(1.31 \mathrm{~g} 100 \mathrm{~g}^{-1}\right)$ yaş meyveye göre daha fazla belirlenmiştir. Etüvde kurutmada sıcaklığa bağlı olarak fumarik asit miktarı düşüş göstermiştir. Fumarik asit miktarı etüvde kurutulan beyaz dutlarda $0.10-0.20 \mathrm{~g} 100 \mathrm{~g}^{-1}$ aralığında tespit edilmiştir. Mikrodalga yöntemiyle kurutulan beyaz dutlarda fumarik asit miktarı düşük olmakla birlikte, 0.08-0.14 g $100 \mathrm{~g}^{-1}$ aralığında tespit edilmiştir. Van ilinden

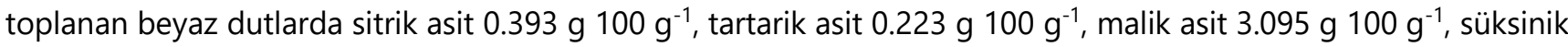

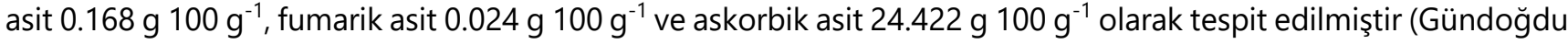
ve ark., 2011). Iğdır'da iki adet beyaz dut genotipi ile yapılan çalışmada, sitrik asit $0.480,0.687 \mathrm{~g} 100 \mathrm{~g}^{-1}$, tartarik 


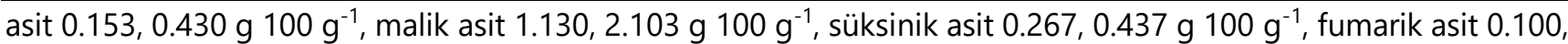
$0.123 \mathrm{~g} 100 \mathrm{~g}^{-1}$ ve askorbik asit 13.400, $18.220 \mathrm{mg} 100 \mathrm{~g}^{-1}$ düzeylerinde belirlenmiştir (Eyduran ve ark., 2015). Bozhüyük ve ark. (2015), yaptıkları çalışmada 3 farklı beyaz dut genotipinde organik asit bileşiminde sitrik asit, tartarik asit, malik asit, süksinik asit, laktik asit, fumarik asit ve asetik asit içeriklerini ortalama olarak sırası ile 0.940-

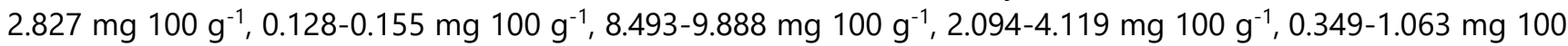
$\mathrm{g}^{-1}, 0.177-0.242 \mathrm{mg} 100 \mathrm{~g}^{-1}$ ve $0.042-0.069 \mathrm{mg} 100 \mathrm{~g}^{-1}$ aralığında tespit etmişlerdir. Iğdır ilinde yapılan bir diğer

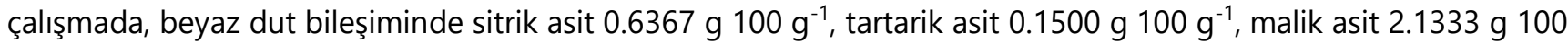

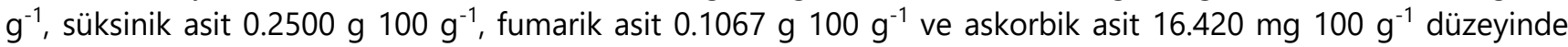
belirlenmiştir (Gecer ve ark., 2016). Hakkari'de yetiştirilen beyaz dut genotiplerinde yapılan çalışmada, organik

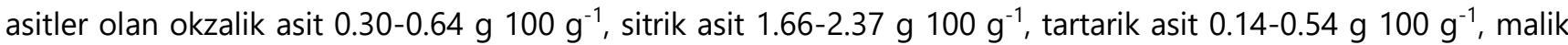

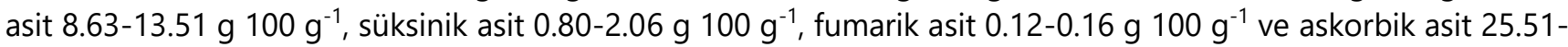
$30.45 \mathrm{mg} 100 \mathrm{~g}^{-1}$ aralığında değişim göstermiştir (Gündoğdu ve ark., 2018). Beyaz dutta elde edilen okzalik asit sonuçları Gündoğdu ve ark. (2018)'in bildirdiği değerler ile benzerlik teşkil etmektedir. Sitrik asit miktarı, Gündoğdu ve ark. (2011), Bozhüyük ve ark. (2015) ve Gündoğdu ve ark. (2018)'ın bildirdiği değerlerin altında, Gecer ve ark. (2016)'ın bildirdiği değerin üzerindedir. İncirde güneşte ve etüvde kurutma yapılmış ve sitrik asit ve malik asit içerikleri incelenmiştir. Kurutma yöntemlerine göre taze incirle kıyaslama yapıldığında sitrik asit ve malik asit içeriklerinde kurutmaya bağlı olarak ciddi artışlar olduğu tespit edilmiştir. Bu sonuçlar, kurutulmuş incirlerin daha az su içermesi yani organik asitlerin konsantre olarak bulunmasına dayandırımıştır (Slatnar ve ark., 2011).

\section{SONUÇ}

Yapılan araştırmada, mikrodalga yöntemli ile kurutulan örneklerde meyve ağırlığındaki düşüş yüzeydeki hızlı kurumaya bağlı olarak diğer yöntemlere kıyasla daha düşük olduğu belirlenmiştir. Etüvde kurutulan örneklerin bazılarında nem oranı güneşte kurutulanlara kıyasla daha yüksek bulunmuştur. Mikrodalga uygulamalarda ise nem oranı daha yüksek oranda belirlenmiştir. Mikrodalga uygulamada nem oranı diğer yöntemlere nazaran daha yüksek bulunmasının nedeni meyvenin kabuğunun aniden kuruması ve içindeki nemi hapsetmesinden kaynaklandığı düşünülmektedir. Bu ürünler daha kuru değil jel formunda ürünler oluşturmuşlardır. Yapılan araştırmada etüvde $\left(110^{\circ} \mathrm{C}\right)$ kurutulan beyaz dut meyve örneklerinde ve güneşte kurutulan karadut meyve örneklerinde en fazla belirlenen organik asittin malik asit olduğu tespit edilmiştir. Doğal kurutulan beyaz dut örneklerinde en fazla belirlenen organik asitlerin malik asit ve sitrik asit olduğu görülmüştür. Etüv ve mikrodalga ile kurutulan örneklerin organik asitlerin değerleri birbirlerine yakın olmakla birlikte güneşte kurutulan örneklerin organik asit miktarları farklılık göstermiştir.

\section{ÇIKAR ÇATIŞMASI}

Yazarlar arasında herhangi bir çıkar çatışması bulunmamaktadır.

\section{YAZAR KATKISI}

Makalenin yazımı ve analiz işlemleri M.K. tarafından yürütülmüştür. Konu dizaynı ve yöntem tercihini M.G. planlanmıştır.

\section{TEŞEKKÜR}

Tez çalışması olan bu araştırma Bolu Abant İzzet Baysal Üniversitesi Bilimsel Araştırma Projeleri Başkanlığınca desteklenmiştir (Proje No: 2017.10.05.1209)

\section{KAYNAKLAR}

Bevilacqua, A. E., \& Califano, A. N. (1989). Determination of organic acids in dairy products by high performance liquid chromatography. Journal of Food Science, 54, 1076-1079.

Bozhüyük, M. R., Pehluvan, M., Kaya, T., \& Doğru B. (2015). Organic acid composition of selected mulberry genotypes from Aras Valley. Atatürk Üniversitesi Ziraat Fakültesi Dergisi, 46(2), 69-74.

Cemeroğlu, B. (2007). Gıda Analizleri. Gıda Teknolojisi Derneği Yayınları. No: 34, Ankara.

Datta, A. K. (2001). Handbook of Microwave Technology for Food Application. CRC Press, USA. 
Ercisli, S, \& Orhan, E. (2007). Chemical composition of white (Morus alba), red (Morus rubra) and black (Morus nigra) mulberry fruits. Food Chemistry, 103(4), 1380-1384.

Ercisli, S. (2004). A short review of the fruit germplasm resources of Turkey. Genetic Resources and Crop Evolution, 51(4), 419435.

Ercisli, S., \& Orhan, E. (2008). Some physico-chemical characteristics of black mulberry (Morus nigra L.) genotypes from Northeast Anatolia Region of Turkey. Scientia Horticulturae, 116, 41-46.

Erdoğan, E. (2003). İspir ve Pazaryolu ilçelerinde yetiştirilen dutların (Morus sp.) seleksiyon yoluyla islahı üzerinde bir araştırma. Doktora Tezi, Atatürk Üniversitesi Fen Bilimleri Enstitüsü, Erzurum.

Erkaleli, Z. Ö., \& Dalkiliç, Z. (2016). Uşak Ili Ulubey ilçesinde yetişen kara dutlarin (Morus nigra L.) morfolojik, fenolojik ve pomolojik özelliklerinin belirlenmesi. Adnan Menderes Üniversitesi Ziraat Fakültesi Dergisi, 13(1), 89-106.

Evranuz, Ö. (1998). Gıda Mühendisliği Tasarımı Ders Notları. İstanbul Teknik Üniversitesi, Gıda Mühendisliği Bölümü, İstanbul.

Eyduran, S. P., Ercisli, S., Akin, M., Beyhan, O., Geçer, M. K., Eyduran, E., \& Erturk, Y. E. (2015) Organic acids, sugars, vitamin C, antioxidant capacity and phenolic compounds in fruits of white (Morus alba L.) and black (Morus nigra L.) mulberry genotypes. Journal of Applied Botany and Food Quality, 88(1), 134-138.

Gecer, M. K., Akin, M., Gündoğdu, M., Eyduran, S. P., Ercisli, S., \& Eyduran, E. (2016). Organic acids, sugars, phenolic compounds, and some horticultural characteristics of black and white mulberry accessions from Eastern Anatolia. Canadian Journal of Plant Science, 96(1), 27-33.

Gündoğdu, M., Muradoglu, F., Sensoy, R. G., \& Yilmaz, H, (2011). Determination of fruit chemical properties of Morus nigra L., Morus alba L. and Morus rubra L. by HPLC. Scientia Horticulturae, 132, 37-41.

Gündoğdu, M., Tunçtürk, M., Berk, S., Şekeroğlu, N., \& Gezici, S. (2018). Antioxidant capacity and bioactive contents of mulberry species from Eastern Anatolia Region of Turkey. Indian Journal of Pharmaceutical Education and Research, 52, 96-101.

Güneş, M., \& Cekiç, Ç. (2004). Some chemical and physical properties of fruits of different mulberry species commonly grown In Anatolia, Turkey. Asian Journal of Chemistry, 16(3), 1849-1855.

Güngör, N., \& Sengul, M. (2008). Antioxidant activity, total phenolic content and selected physicochemical properties of white mulberry (Morus alba L.) fruits. International Journal of Food Properties, 11(1), 44-52.

Imran, M., Khan, H., Shah, M., Khan, R., \& Khan, F. (2010). Chemical composition and antioxidant activity of certain Morus Species. Journal of Zhejiang University Science B, 11(12), 973-980.

Juhaimi, F. A., Özcan, M. M., \& Uslu, N. (2017). The effect of microwave and conventional drying on antioxidant activity, phenolic compounds and mineral profile of date fruit (Phoenix dactylifera L.) flesh. Journal of Food Measurement and Characterization, 11, 58-63.

Koyuncu, F. (2004). Organic acid composition of native black mulberry fruit. Chemistry of Natural Compounds, 40(4), $367-369$.

Koyuncu, F., Çetinbas, M., \& Erdal, İ. (2014). Nutritional constituents of wild-grown black mulberry (Morus nigra L.). Journal of Applied Botany and Food Quality, 87, 93-96.

Oliveira, M. E. C., \& Franca, A. S. (2002). Microwave heating of foodstuffs. Journal of Food Engineering, 53(4), $347-359$.

Pehluvan, M., Kaya, T., Doğru, B., \& Bozhüyük, M. R. (2012). Farklı lokasyon ve hasat zamanlarının kara dutun (Morus nigra L.) bazı meyve özellikleri üzerine etkisi. IV. Ulusal Üzümsü Meyveler Sempozyumu, Antalya.

Rop, O., Ercıslı, S., Mlcek, J., Jurıkova, T., \& Hoza, I., (2014). Antioxidant and radical scavenging activities in fruits of 6 sea buckthorn (Hippophae rhamnoides L.) cultivars. Turkish. Journal of Agriculture and Forestry, 38, $224-232$.

Sanchez, E. M., Calın-Sanchez, A., Carbonell-Barrachına, A. A., Mel-Garejo, P., Hernandez, F., \& Martınez-Nıcolas, J. J. (2014). Physicochemical characterization of eight Spanish mulberry clones: Processing and fresh market aptitudes. International Journal of Food Science and Technology. 49, 477-483.

Sanchez-Salcedo, E. M., Mena, P., Garcıa-Vıguera, C., Martınez, J. J., \& Hernandez, F. (2015). Phytochemical evaluation of white (Morus alba L.) and black (Morus nigra L.) mulberry fruits, a starting point for the assessment of their beneficial properties. Journal of Functional Foods, 12, 399-408.

Slatnar, A., Klancar, U., Stampar, F., \& Veberic, R. (2011). Effect of drying of figs (Ficus carica L.) on the contents of sugars, organic acids, and phenolic compounds. Journal Of Agricultural and Food Chemistry, 59(21), 11696-11702.

Verheij, E. W. M., \& Coronel, R. E. (1991). Plant resources of South-East Asia 2. Edible Fruits and Nuts. 348, Netherlands. 